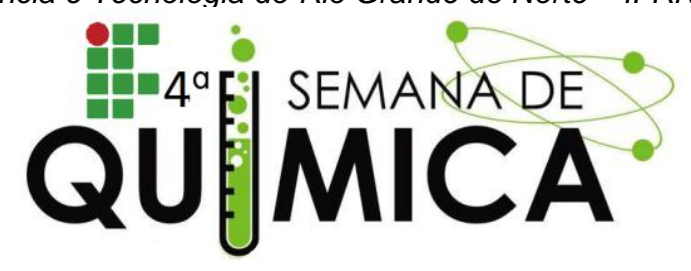

\title{
DETERMINAÇÃO DA ATIVIDADE ANTIOXIDANTE DOS EXTRATOS DAS FOLHAS VERDES E SECAS DA VITEX GARDNERIANA SHAUER (JARAMATAIA)
}

SABINO, B. T. S1 (IFRN), COSTA, A. K. M² (IFRN), DE PAIVA, L. M. M³ (IFRN) e DA SILVA, F. F. M (IFRN).

Oxidantes são compostos produzidos pelo metabolismo normal do corpo e, se não controlados, podem provocar danos extensivos. E para conter a ação de substâncias oxidantes os antioxidantes são capazes de estabilizar ou desativar os radicais livres antes que ataquem os alvos biológicos nas células. Desta forma, o presente trabalho tem como objetivo, estudar a atividade antioxidante dos extratos das folhas secas e verdes em etanol da Vitex Gardneriana Shauer.

Palavras Chave: Vitex Gardneriana Shauer, Atividade Antioxidante, Radical Livre DPPH.

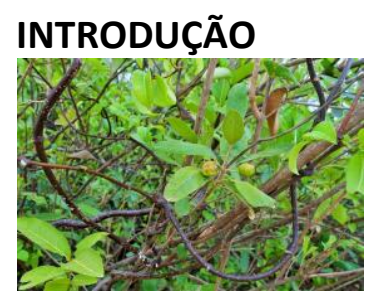

Devido às propriedade das substâncias antioxidantes em capturar radicais, estas têm sido utilizadas nos mais variados tratamentos de patologias. (ROESLER, et al, 2007). Nesse sentido, o presente trabalho teve como objetivo avaliar o potencial antioxidante de extratos feito em etanol das folhas da Jaramataia (Vitex Gardneriana Shauer). Isso devido ao fato desta planta está sendo utilizada extensivamente por algumas comunidades da cidade de APODI-RN e região, sendo que o conhecimento popular atribui muitas atividades biológicas as mesmas, tais como: formas naturais de medicamentos para dores na coluna, dores de cabeça, dores musculares e nódulos.

\section{METODOLOGIA}

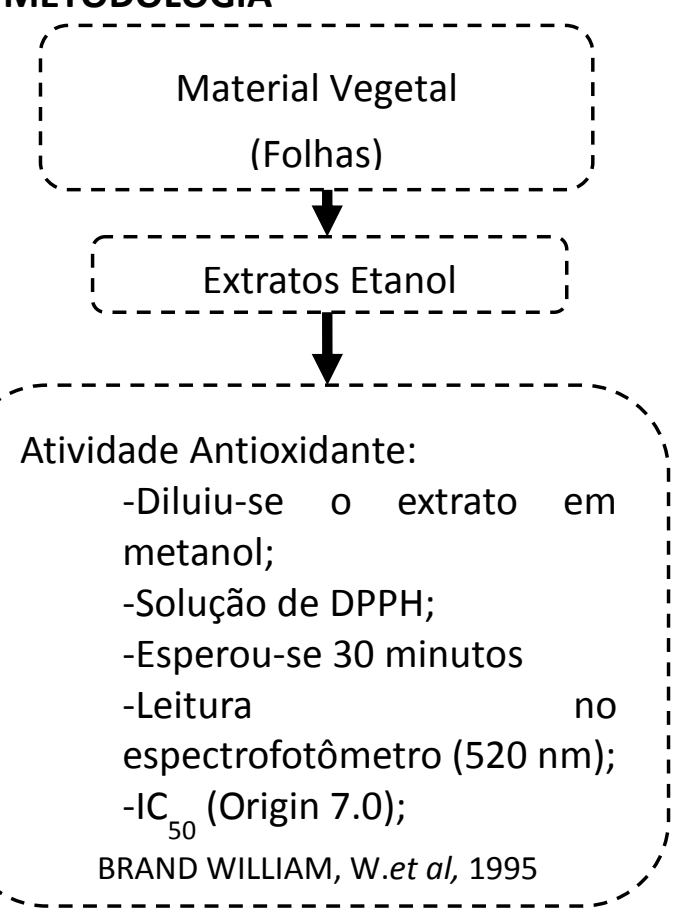

\begin{tabular}{|l|c|}
\hline \multicolumn{2}{|c|}{ Atividade Antioxidante $\left(\mathbf{I C}_{\mathbf{5 0}}\right)$} \\
\hline Folhas Verdes Etanol & $3,86 \mathrm{ppm}$ \\
\hline Folhas Secas Etanol & $3,48 \mathrm{ppm}$ \\
\hline TROLOX & $4,07 \mathrm{ppm}$ \\
\hline
\end{tabular}

Tabela 1- Atividade Antioxidante obtida pelo método do DPPH da Vitex Gardneriana Shauer RESULTADOS E DISCUSSÕES

Mediante observações, nota-se que tanto o extrato das folhas verdes, quanto o das folhas secas apresentaram uma boa atividade antioxidante, quando comparada ao padrão positivo utilizado, TROLOX.

\section{CONCLUSÃO}

Diante destes resultados, é possível dizer que a atividade antioxidante das folhas da Vitex Gardneriana Shauer foi bem significativa, quando comparada ao padrão positivo utilizado, TROLOX. Vale ressaltar que, pretende-se a realização de outros testes biológicos, como, por exemplo, o de toxicidade para uma melhor avaliação da planta em estudo.

\section{REFERÊNCIAS}

1 BRAND-WILLIAMS, W. et al. Use of a free radical method to evaluate antioxidant activity. Lebensmittel - Wissenschaft Technologie. v. 28, n. 1, p. 25-30, 1995.

2 ROESLER, R.; MALTA, L. G.; CARRASCO, L. C.; HOLANDA, R. B.; SOUSA, C. A. S.; PASTORE, G.M. Atividade antioxidante de plantas, 2007. 